Original Research Paper

\title{
Phytoplankton Diversity as Bioindicator of Pandanduri Dam Waters, East Lombok Regency
}

\author{
Lalu Hasan Nasirudin Zohri ${ }^{1}$, Agil Al Idrus ${ }^{1^{*}}$, Lalu Japa ${ }^{1}$ \\ ${ }^{1}$ Program Srudi Pendidikan Biologi Universitas Mataram, Mataram, Indonesia
}

\author{
Article History \\ Received : August $20^{\text {th }}, 2020$ \\ Revised : September $05^{\text {th }}, 2020$ \\ Accepted : September $08^{\text {th }}, 2020$ \\ Published : October $15^{\text {th }}, 2020$ \\ *Corresponding Author: \\ Agil Al Idrus, \\ Program Studi Pendidikan \\ Biologi Universitas Mataram, \\ Mataram, Indonesia \\ Email: agilalidrus@gmail.com
}

\begin{abstract}
Pandanduri Dam waters has an essential function for the community made the activities of the surrounding community inseparable from the Pandanduri Dam that made potentially quality change of the Pandanduri Dam waters. Good water quality is an important requirement for humans that made water quality research is essential to be done. Human activities will affect environmental factors such as biological parameters, especially phytoplankton, which are indicators of water quality. The aim of this study was to analyzed water quality of Pandanduri Dam through study of phytoplankton community and diversity. Sample sites were determined based on haphazard sampling method and phytoplankton data were analyzed based on the shannon-weiner diversity index. The results showed that the phytoplankton community identified in Pandanduri Dam consisted of 5 classes, 13 orders, and 31 species with species diversity index of 2,659. Based on fitoplankton diversity index value the water of Pandanduri Dam was in lightly polluted category. It is suggested to more detailed studies should be undertaken especially on species that produce toxins over a longer time scale.
\end{abstract}

Keywords: Pandanduri Dam; Phytoplankton Diversity Index; Water Quality

\section{Pendahuluan}

Bendungan Pandanduri terletak di Kecamatan Terara dan Sakra, Kabupaten Lombok Timur, memiliki fungsi esensial bagi masyarakat di sekitar bendungan. Aktivitas masyarakat di sekitar bendungan seperti kegiatan pertanian dan keramba jaring apung dikawatirkann dapat mempengaruhi kualitas perairan Bendungan Pandanduri. Kegiatan pertanian dengan komuditas utama padi dan tembakau umumnya menggunakan pupuk ZA (300 kg/ha), urea (50-100 kg/ha), NPK (600 kg/ha) kemudian kegiatan keramba jaring apung melalui pemberian pakan pellet terhadap ikan dikhawatirkan memiliki sumbangsih material organik yang besar terhadap perairan bendungan Pandanduri. Material organik yang terlarut dalam air bendungan dapat mempengaruhi kualitas lingkungan perairan (Suriadarma, 2011). Aktivitas manusia seperti kegiatan diatas akan mempengaruhi faktor lingkungan seperti parameter biologi terutama fitoplankton yang menjadi penanda kualitas air (Simanjuntak, 2009).

Fitoplankton merupakan organisme yang dapat digunakan sebagai parameter lingkungan untuk menggambarkan keadaan yang terjadi pada lingkungan perairan. Organisme yang dijadikan

This article is licensed under a Creative Commons Attribution 4.0 International License. parameter lingkungan disebut bioindikator. Menurut Purwati (2016) bioindikator adalah kelompok atau komunitas organisme yang kehadirannya atau perilakunya di alam berkorelasi dengan kondisi lingkungan, sehingga dapat digunakan sebagai petunjuk kualitas lingkungan. Penggunaan fitoplankton sebagai bioindikator dalam menggambarkan kualitas air dikarenakan keberadaan fitoplankton yang erat kaitannya dengan perubahan lingkungan yang diakibatkan oleh pencemaran (Wijaya dan Hariyati, 2011). Parameter fitoplankton dapat menggambarkan kualitas air didasarkan pada ketergantungan fitoplankton terhadap kualitas air dan berhubungan erat dengan aktivitas manusia (Odulate et al., 2017). Kualitas air yang direpresentasi oleh keadaan faktor-faktor lingkungan akan menentukan kelompok fitoplankton yang mendiami suatu perairan (Nwonumara, 2018). Jumlah jenis dan individu fitoplankton akan mendeterminasi nilai indeks keanekragaman yang akan menentukan tingkat pencemaran suatu perairan.

Kualitas air yang baik menjadi kebutuhan penting bagi manusia dan makhluk hidup lainnya dan isu pencemaran air menjadi masalah yang terus berlangsung membuat penelitian kualitas air menjadi hal yang penting untuk dilakukan. Keadaan ini 
memerlukan pengelolaan berkelanjutan terhadap wilayah sungai termasuk Bendungan Pandanduri yang membutuhkan informasi tentang kualitas air. Informasi dan data tentang kualitas air di Bendungan Pandanduri belum banyak yang dipublikasikan sepanjang pengetahuan peneliti. Data ini sangat penting untuk perencanaan, pengelolaan, dan pemanfaatan perairan Bendungan Pandanduri terlebih adanya kegiatan jaring apung di dalam bendungan dan kegiatan agrikultur disekitar bendungan dapat menjadi penurun kualitas perairan. Berdasarkan latar belakang tersebut peneliti memandang perlu adanya penelitian tentang "Keanekaragaman Fitoplankton Sebagai Bioindikator Perairan Bendungan Pandanduri Kabupaten Lombok Timur".

\section{Bahan dan Metode}

\section{Waktu dan Waktu Penelitian}

Jenis penelitian yang digunakan adalah deskriptif eksploratif. Lokasi pengambilan sampel dilakukan di Bendungan Pandanduri kumudian identifikasi fitoplankton di Laboratorium Biologi Fakultas Keguruan dan Ilmu Pendidikan Universitas Mataram. Waktu pengambilan sampel dilakukan pada bulan Februari 2020, kemudian indentifikasi dan analisis data fitoplankton dilakukan pada bulan Maret hingga April 2020.

\section{Populasi dan Sampel}

Populasi dari penelitian ini adalah seluruh air yang terdapat di Bendungan Pandanduri. Sedangkan sampel penelitian adalah air yang diambil dari setiap titik sampel dan disimpan pada botol sampel. Titik sampel ditentukan berdasarkan teknik haphazard sampling method berjumlah 5 titik yang terdiri dari dua pada sisi inlet, dua pada sisi midlet, dan satu pada sisi outlet (Gambar 1, Tabel 1).

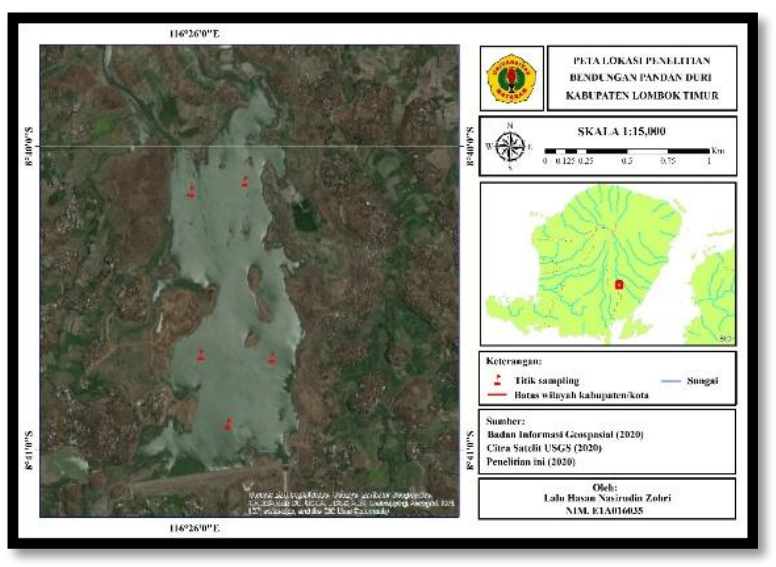

Gambar 1. Peta bendungam Pandanduri.
Tabel 1. Titik kordinat sampel di bendungan Pandanduri

\begin{tabular}{lcc}
\hline \multicolumn{1}{c}{ Nama Stasiun } & \multicolumn{2}{c}{ Posisi Geografis } \\
\cline { 2 - 3 } & Longitude & Latitude \\
\hline Titik I (outlet) & $8^{\circ} 40.5680^{\prime} \mathrm{S}$ & $116^{\circ} 25.3680^{\prime} \mathrm{E}$ \\
Titik II (midlet barat) & $8^{\circ} 39.9540$ 'S & $116^{\circ} 26.5160^{\prime} \mathrm{E}$ \\
Titik III (inlet barat) & $8^{\circ} 40.9480 ' \mathrm{~S}$ & $116^{\circ} 26.8900^{\prime} \mathrm{E}$ \\
Titik IV (inlet timur) & $8^{\circ} 40.2240$ 'S & $116^{\circ} 26.9600^{\prime} \mathrm{E}$ \\
Titik V (midlet timur) & $8^{\circ} 40.8420^{\prime} \mathrm{S}$ & $116^{\circ} 26.1900^{\prime} \mathrm{E}$ \\
\hline
\end{tabular}

\section{Prosedur Pengambilan Data}

Pengambilan sampel fitoplankton dilakukan dengan mengambil air dari bagian permukaan sebanyak 100 liter menggunakan ember berukuran 5 liter (sebanyak dua puluh kali) kemudian disaring menggunakan jaring plankton berukuran $20 \mu \mathrm{m}$. Sampel air kemudian diawetkan menggunakan formalin dengan konsentrasi 5\%. Penentuan jenis fitoplankton berdasarkan karakteristik morfologi yang tampak seperti bentuk, struktur dinding sel, dan bentuk koloni. Sumber yang digunakan dalam identifikasi berdasar pada Al-Kandari et. al. (2009), Barsanti dan Gualtieri (2014), Park (2012), Kim dan Kim (2012), Bellinger dan Sigee (2010), Chapman (1962), Tomas (1997), dan Sahoo dan Seckbach (2015).

\section{Analisis Data}

Analisis data keanekaragaman fitoplankton berdasarkan indeks keanekaragaman shannon-weiner kemudian tingkat pencemaran berdasarkan kriteria indeks keanekaragaman kategori pencemaran Mason (1981) daam Agustina dan Mpoke (2016) (Tabel 2). Spesies yang paling dominan terhadap keanekragaman dideskripsikan menggunakan analisis kelimpahan fitoplankton.

Tabel 2. Kriteria indeks keanekaragaman kategori pencemaran

\begin{tabular}{ccc}
\hline $\begin{array}{c}\text { Indeks } \\
\text { Keanekaragaman }\end{array}$ & $\begin{array}{c}\text { Kategori } \\
\text { Keanekaragaman }\end{array}$ & $\begin{array}{c}\text { Kategori } \\
\text { Pencemaran }\end{array}$ \\
\hline$>3$ & Tinggi & Belum tercemar \\
$2,5-3$ & Cukup tinggi & Tercemar ringan \\
$1-<2,5$ & Sedang & Tercemar sedang \\
$<1$ & Rendah & Tercemar berat \\
\hline
\end{tabular}

\section{Indeks Keanekaragaman}

Keanekaragaman komunitas dapat dihitung dengan menggunakan indeks keanekaragaman menggunakan rumus indeks Shannon-Weiner (Alidrus, 2014). Indeks Shannon-Weiner merupakan perhitungan dari logaritma jumlah individu suatu spesies dibagi dengan individu total yang mana semakin tinggi nilai indeks mengindikasikan semakin 
tinggi tingkat keanekaragaman (Odum dan Barrett, 1993). Adapun persamaan Shannon-Weiner yang tertera pada Odum \& Barrett (1993) adalah sebagi berikut:

$$
\mathrm{H}^{\prime}=-\sum \mathrm{P}_{\mathrm{i}} \operatorname{Ln} \mathrm{P}_{\mathrm{i}}
$$

Keterangan:

H' : Indeks Keanekaragaman Shannon

$\mathrm{Pi} \quad$ : Jumlah individu spesies dibagi jumlah total individu

\section{Kemelimpahan Spesies}

Kelimpahan fitoplankton dinyatakan dalam individu per-liter dimana untuk mencari kelimpahan fitoplankton dilakukan Pencacahan fitoplankton melalui penghitungan jumlah sel fitoplankton. Fitoplankton yang berbentuk rantai atau koloni dihitung jumlah sel dalam rantai atau koloni sebagai jumlah individu. Perhitungan jumlah sel fitoplankton menggunakan rumus (Romimohtarto dan Juwana, 2007):

$$
\mathrm{N}=\frac{\mathrm{n}}{\mathrm{m}} \times \frac{\mathrm{s}}{\mathrm{a}} \times \frac{1}{\mathrm{v}}
$$

\section{Keterangan:}

$\mathrm{N}=$ jumlah sel per $\mathrm{m}^{3}$

$\mathrm{n}=$ jumlah sel yang dihitung dalam $\mathrm{m}$ tetes

$\mathrm{m}=$ jumlah tetes contoh yang diperiksa

$\mathrm{s}=$ volume contoh dengan pengawetannya $(\mathrm{ml})$

$\mathrm{a}=$ volume tiap tetes contoh (menggunakan pipet otomatik $0.05 \mathrm{ml}$ )

$\mathrm{v}=$ volume air tersaring $(\mathrm{L})$

\section{Hasil dan Pembahasan}

\section{Komunitas Fitoplankton}

Penelitian ini berhasil mengidentifikasi 31 spesies fitoplankton yang terdiri dari 5 kelas, dan 13 ordo yang teridentifikasi. Distribusi kelas merata sebanyak 5 tiap titik sampel. Ordo tertinggi sebanyak 12 terdapat pada titik II, III, dan V. Kemudian spesies tertinggi terdapat pada titik I sebanyak 27 spesies (Gambar 2).

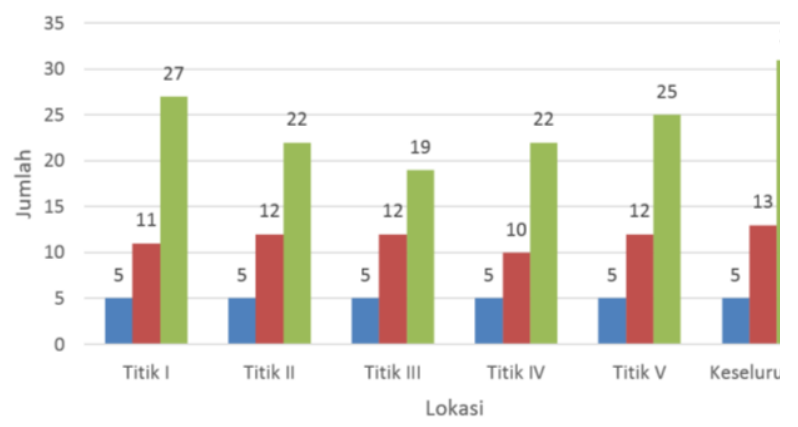

Gambar 2. Jumlah taksa tiap titik sampel
Adapun 5 kelas yang ditemukan terdiri dari Chlorophyceae, Cyanophyceae, Bacillariophyceae, Euglenophyceae, dan Dinophyceae. Ordo dan spesies terbanyak ditemukan pada kelas Chlorophyceae (Gambar 3).

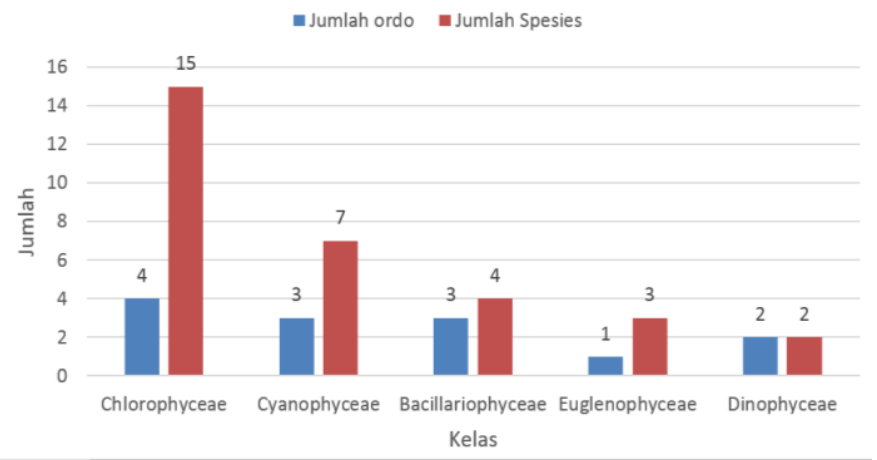

Gambar 3. Persebaran taksa yang ditemukan pada tiap kelas

\section{Kelimpahan Fitoplankton}

Analisis kelimpahan fitoplankton menunjukkan adanya blooming salah satu spesies dekarenakan terjadi ledakan jumlah individu dari spesies Cylindrospermofsis raciborskii membuat spesies ini sangat dominan di perairan Bendungan Pandanduri. Cylindrospermofsis raciborskii merupakan spesies dengan kelimpahan tertinggi dengan 4519,167 ind/L. Di sisi lain Gymnodynium sp. memiliki kelimpahan paling rendah dengan 9,167 ind/L (Gambar 5).

\section{Keanekaragaman Fitoplankton}

Fitoplankton Bendungan Pandanduri menunjukkan indeks keanekaragaman spesies sebesar 2,660 dan bervariasi antar titik sampel, titik I menunjukkan indeks keanekaragaman tertinggi dengan nilai 2,626 dan indeks keanekragaman paling rendah terdapat pada titik III dengan nilai 2,256 (Gambar 4). Secara keseluruhan nilai indeks keanekagaman spesies fitoplankton menunjukkan perairan Bendungan Pandanduri termasuk ke dalam perairan dengan kategori tercemar ringan.

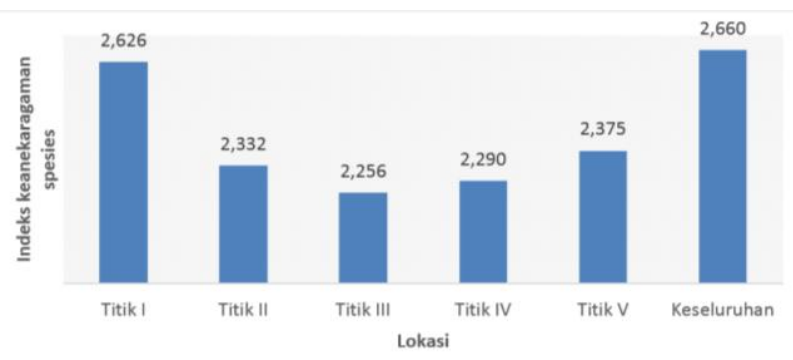

Gambar 4. Indeks keanekaragaman spesies fitoplankton tiap titik sampel 


\section{Komunitas Fitoplankton}

Fitoplankton perairan Bendungan Pendanduri Lombok Timur tahun 2020 teridentifikasi sebanyak 5 kelas, 13 ordo, dan 31 spesies. Adapun 5 kelas terdiri dari Chlorophyceae (15 spesies), Cyanophyceae (7 spesies), Bacillariophyceae (4 spesies), Euglenophyceae (3 spesies), dan Dinophyceae (2 spesies) (Gambar 2). Hasil ini menunjukkan jumlah spesies cenderung lebih sedikit dibandingkan beberapa perairan di wilayah Nusa Tenggara Barat. Fitoplankton Sungai Pelangan Lombok Barat memiliki jumlah spesies yang tinggi yaitu 50 akan tetapi hanya terdiri dari dua divisi (Astuti et al., 2017). Danau Lebo Taliwang menunjukkan jumlah kelas, ordo dan spesies jauh lebih tinggi terdiri dari 10 kelas dengan 14 ordo dan 48 spesies (Kawirian, 2018). Di sisi lain, laporan Budiarsih (2019) menunjukkan fitoplankton pada sumber air panas di kawasan Taman Nasional Gunung Rinjani yang diambil dari dua lokasi sumber air panas yakni sumber air panas Sebau dan Aik-Kalak memiliki ordo dan spesies yang lebih sedikit dibandingkan Bendungan Pandanduri, terdiri dari 11 ordo dan 20 spesies. Terdapat kenaikan jumlah kelas dan spesies yang ditemukan di Bendungan Pandanduri dibandingkan tahun 2016. Laporan Mardani et al. (2016) menunjukkan tidak ditemukan kelas Euglenophyceae dan hanya ditemukan 14 spesies fitoplankton.

Terdapat variasi persebaran jumlah spesies fitoplankton antar titik sampel di Bendungan Pandanduri. Titik I yang merupakan daerah hilir memperlihatkan jumlah spesies tertinggi yaitu sebanyak 27 spesies sedangkan titik III yang merupakan daerah hulu memperlihatkan jumlah spesies paling sedikit yaitu 19 spesies (Gambar 2). Hal ini menunjukkan bahwa daerah hulu cenderung memiliki jumlah spesies yang lebih sedikit dibandingkan dengan daerah hilir. Hal yang sama dilaporkan oleh Hutabarat et al. (2013) titik I yang merupakan daerah hulu memiliki jumlah spesies yang lebih sedikit dibandingkan titik sampel lainnya di Sungai Babon Semarang. Tingginya spesies fitoplankton di titik I dikarenakan merupakan daerah hilir yang kaya akan material organik. Daerah ini merupakan akhir dari semua aliran di setiap titik sampel sehingga semua bahan organik dan plankton mengalir ke daerah ini, sedangkan di daerah inlet/hulu merupakan daerah dengan kandungan bahan organik lebih rendah atau belum adanya tambahan masukan bahan organik (Mardani et al., 2016).

Secara keseluruhan kelas Chlorophyceae memiliki jumlah spesies tertinggi dengan 15 spesies (Gambar 3). Hal yang sama dinyatakan oleh Munthe et al. (2012) di mana Chlorophyceae merupakan kelompok fitoplankton paling banyak ditemukan pada perairan air tawar. Keadaan jumah spesies yang tinggi pada kelas Chlorophycea sangat kontras dengan jumlah individu yang ditemukan. Jumlah individu tertinggi dimiliki oleh kelas Cyanophyceae, keadaan ini terjadi pada seluruh titik sampel. Keadaan ini disebabkan karena adanya perbedaan daya toleransi masing-masing kelas. Aziz (2015) mengatakan Cyanophyceae dan Chlorophyceae merupakan jenis fitoplankton dominan di perairan yang tergenang, namun karena Cyanophyceae lebih dapat bertoleransi terhadap kisaran suhu yang lebih tinggi dibandingkan dengan Chlorophyceae dan Bacillariophyceae sehingga pada perairan ini lebih didominasi oleh Cyanophyceae. Selain itu, tingginya jumlah individu kelas Cyanophyceae diakibatkan adanya blooming dari spesies Cylindrospermopsis raciborskii.

\section{Kelimpahan Fitoplankton}

Cylindrospermopsis raciborskii sangat dominan di perairan Bendungan Pandanduri. Keadaan ini dikarenakan spesies tersebut memiliki toleransi fisiologis yang sangat tinggi membuat spesies ini memiliki daya saing yang sangat tinggi (Isvanovic et al., 2000; Briand et al., 2004), terlebih sumbangsih material organik seperti posfat dan nitrat dari pupuk dan pakan ikan dari kegiatan jaring apung dan agrikultur mengoptimalkan pertumbuhan Cylindrospermopsis raciborskii (Amaral et al., 2014). Di sisi lain, Gymnodinium sp. memiliki kelimpahan paling rendah dan hanya ditemukan pada titik $\mathrm{V}$ (Gambar 5). Gymnodinium sp. memiliki kelimpahan yang rendah dikarenakan suhu perairan yang tinggi $\left(29^{\circ} \mathrm{C}-30^{\circ} \mathrm{C}\right)$ di mana suhu optimal spesies ini berkisar $22^{\circ} \mathrm{C}-28^{\circ} \mathrm{C}$ (Bravo dan Anderson, 1994).

Kelimpahan yang sanat tinggi dari spesies fitoplankton Cylindrospermopsis raciborskii yang merupakan anggota kelas Cyanophyceae perlu mendapat perhatian. Perairan yang didominasi oleh anggota Cyanophyceae perlu mendapatkan perhatian secara khusus, karena pada umumnya anggota divisi ini menghasilkan toksin yang disebut cyanotoksin (Sahoo dan Seckbach, 2015). Cylindrospermopsis raciborskii merupakan spesies fitoplankton air tawar yang diketahui menghasilkan alkaloid cylindrospermopsin, toksin PSP (paralytic shellfish poisoning) dan beberapa komponen yang tidak diketahui (Bellinger dan Sigee, 2010). Terdapat dua tipe toksin yang diproduksi oleh Cyanophyceae yang secara umum disebut hepatotoksin dan neurotoksin. Hepatotoksin menyebabkan pemecahan sel hati, dan organ internal lain dari korban yang terkena racun dan menyebabkan kematian melalui internal haemorrhage. Neurotoksin menyerang sistem saraf korban yang teracuni dan mengarah kematian karena kerusakan sistem pernapasan. Spesies yang termasuk 
hepatotoksik melingkupi Microcystis aeruginosa, Nodularia spumigena, dan Cylindrospermopsis raciborskii (Rissik et al., 2009).

\section{Keanekaragaman Fitoplankton}

Indeks keanekaragaman spesies fitoplankton Bendungan Pandanduri secara keseluruhan adalah 2,659 (Gambar 4). Menurut Fitriana (2006) keanekaragaman dengan rentang $1,0<\mathrm{H}^{\prime}<3,22$ termasuk dalam kategori keanekaragaman sedang. Indeks keanekragaman spesies fitoplankton Bendungan Pandanduri lebih tinggi dibanding Danau Lebo dengan indeks 1,819 (Kawirian et al, 2018). Perairan air panas wilayah Taman Nasional Gunung Rinjani memperlihatkan angka yang lebih rendah, Budiarsih (2019) melaporkan total indeks keanekaragaman spesies fitoplankton air panas Sebau adalah 0,02 sedangkan pada Aik Kalak 1,8. Sungai Pelangan Kabupaten Lombok Barat memperlihatkan indeks keanekaragaman yang lebih tinggi, Astuti et al. (2017) melaporkan salah satu lokasi sungai memiliki indeks sebesar 3,010.

Indeks keanekaragaman spesies tertinggi terdapat pada titik I dengan 2,626 sedangkan titik III memperlihatkan indeks keanekaragaman paling rendah yaitu 2,256 (Gambar 4). Tingginya indeks keanekaragaman spesies pada titik I dikarenakan daerah hilir tempat terakumulasinya berbagai zat terlarut yang dapat berfungsi sebagai nutrisi untuk fitoplankton. Mardani et al. (2016) menyatakan daerah hilir merupakan tempat terakumulasinya berbagai zat terlarut yang sangat mempengaruhi perairan. Rendahnya indeks keanekaragaman pada titik III dikarenakan merupakan daerah hulu yang masih memiliki arus. Astuti et al. (2017) menyatakan rendahnya indeks keanekaragaman jenis dapat disebabkan merupakan daerah aliran sungai. Hal tersebut dikarenakan lokasi ini masih memiliki arus yang tinggi sehingga individu dan jenis fitoplankton lebih rendah (Mardani et al., 2016). Menurut pendapat Barus (2004) yang menyatakan bahwa suatu komunitas akan mempunyai keanekaragaman jenis yang tinggi apabila terdapat banyak jenis dengan jumlah individu masing masing jenis yang relatif merata.

\section{Keanekaragaman Fitoplankton Sebagai Bioindikator Perairan}

Berdasarkan kriteria indeks keanekaragaman kategori pencemaran Mason (1981) nilai indeks keanekaragaman spesies fitoplankton Bendungan Pandanduri tergolong dalam perairan dengan tercemar ringan. Agustina dan Mpoke (2016) menyatakan nilai indeks keanekaragaman 2,5-3 termasuk dalam kategori tercemar ringan. Faktor utama yang mempengaruhi indeks keanekaragaman dan kualitas air dari segi fitoplankton adalah keberadaan spesies Cylindrospermopsis raciborskii yang sangat dominan (Gambar 5). Berdasarkan persamaan indeks keanekaragaman Shannon-weiner dalam Odum dan Barret (1993) menunjukkan semakin merata jumlah indipidu untuk tiap spesies menyebabkan semakin tinggi indeks keanekaragaman. Barus (2004) menyatakan suatu komunitas akan mempunyai keanekaragaman jenis yang tinggi apabila terdapat banyak jenis dengan jumlah individu masing masing jenis yang relatif merata. Ledakan jumlah spesies Cylindrospermopsis raciborskii menyebabkan perbedaan jumlah individu yang tinggi antar spesies. Perbedaan jumlah inidividu tersebut mengakibatkan rendahnya nilai inideks keanekaragaman spesies fitoplankton. 
Lalu Hasan Nasirudin Zohri et al. (2020). Jurnal Biologi Tropis, 20 (3): 355 - 362 DOI: http://dx.doi.org/10.29303/jbt.v20i3.2024

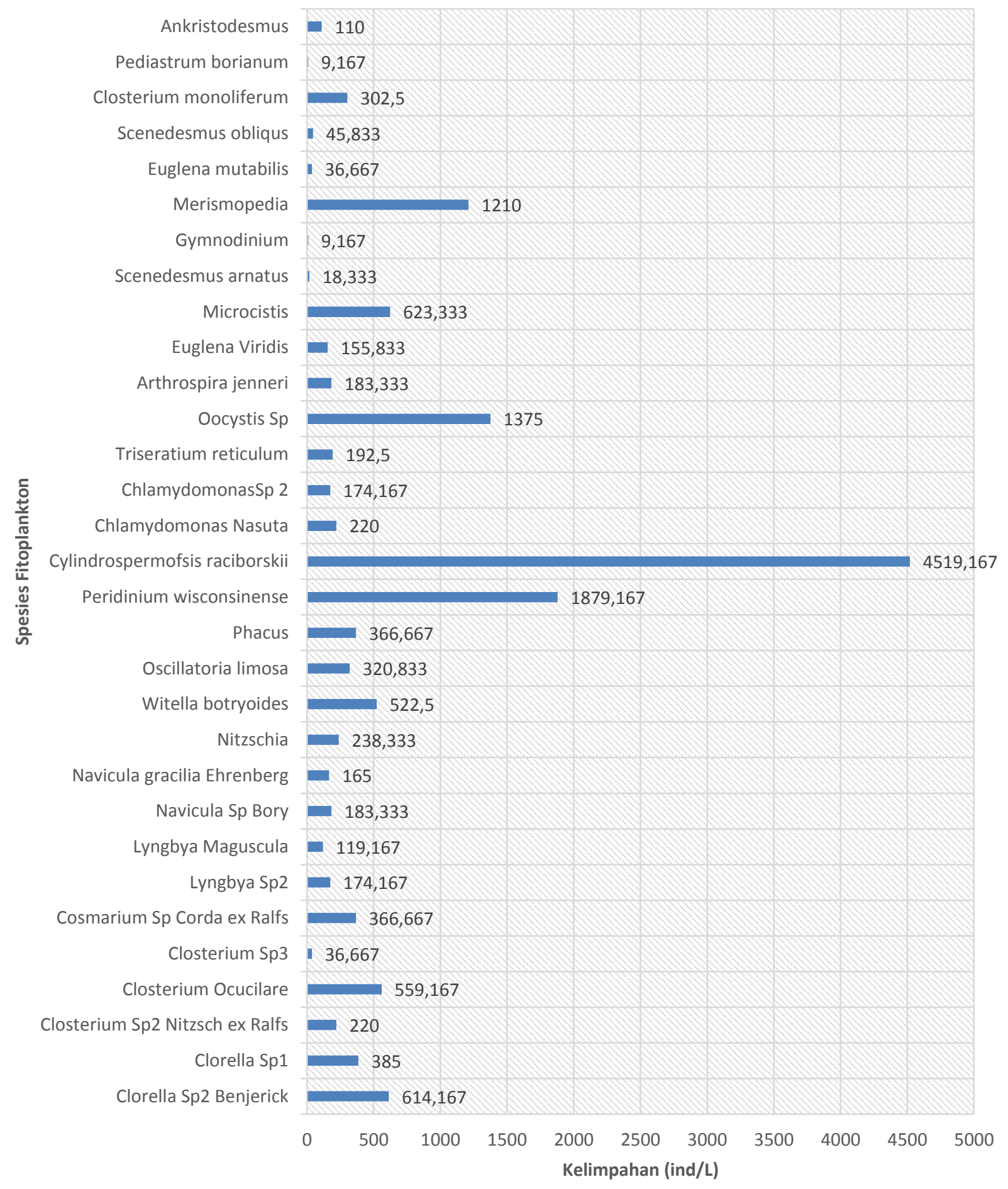

Gambar 5. Kelimpahan tiap spesies fitoplankton (ind/L) di Bendungan Pandanduri

\section{Kesimpulan}

Berdasarkan hasil penelitian ini dapat disimpulkan bahwa komunitas fitoplankton bendungan Pandanduri Kabupaten Lombok Timur terdiri dari 5 Kelas, 13 ordo, dan 31 spesies dengan indeks keanekaragaman fitoplankton Bendungan Pandanduri secara keseluruhan adalah 2,659 tergolong dalam perairan dengan tercemar ringan yang diakibatkan meledaknya jumlah spesies Cylindrospermopsis raciborskii yang mempengaruhi nilai indeks keanekaragaman. 


\section{Ucapan terima kasih}

Penulis menyampaikan terima kasih kepada FKIP Universitas Mataram yang menyediakan laboratorium kemudian BWS Nusa Tenggara I yang mengizinkan penelitian serta rekan-rekan P. Biologi yang telah banyak membantu.

\section{Referensi}

Agustina, S. S. dan Mpoke, A. A. (2016). Keanekaragaman Fitoplankton Sebagai Indikator Tingkat Pencemaran Perairan Teluk Lalong Kota Luwuk. Jurnal Balik Diwa. 7 (2): 1-6. https://stitekbalikdiwa.ac.id/e-jurnal-issue/volume-7/ (Accessed on May 13, 2020).

Al-Idrus, A. (2014). Mangrove Gili Sulat Lombok Timur. Mataram: Arga Puji Press.

Al-Kandari, M., Al-Yamani, F. \& Al-Rifaie, K. (2009). Marine Phytoplankton Atlas of Kuwaits Waters. Safat: Kuwait Institute for Saintific Research.

Amaral, V., Bonilla, S. \& Aubriot, L. (2014). Growth Optimazation of the Invasive Cyanobacterium Cylindrospermopsis raciborskii in Response to Phosphate Fluctuation. European Journal of Phycology. 49 (1): 134-141. DOI: 10.1080/09670262.2014.897760.

Astuti, W., Astuti, S. P. \& Japa, L. (2017). Komunitas Mikroalga di Perairan Sungai dan Muara Sungai Pelangan Kecamatan Sekotong Kabupaten Lombok Barat. Jurnal Biologi Tropis. 22 (1): 76-86. DOI: http://dx.doi.org/10.29303/jbt.v17i1.401.

Aziz, R., Nirmala, K., Affandi, R. \& Prihadi, T. (2015). Kelimpahan Plankton Penyebab Bau Lumpur pada Budidaya Ikan Bandeng Menggunakan Pupuk N:P. Jurnal Akuakultur Indonesia. 14 (1): 58-68. DOI: https://doi.org/10.19027/jai.14.58-68.

Barus, T. A. (2004). Faktor-faktor Lingkungan Abiotik dan Keanekaragaman Plankton Sebagai Indikator Kualitas Perairan Danau Toba. Manusia dan Lingkungan. 11 (2): 6472.

DOI:

https://doi.org/10.22146/jml.18620.
Barsanti, L. \& Gualtieri, P. (2014). Algae Anatomy, Biochemistry, and Biotechnology Second Edition. Boca Raton: Chemical Rubber Company Press.

Bellinger, E. G. \& Sigee, D. C. (2010). Freshwater Algae Identification and Use as Bioindicators. Chichester: John Wiley and Sons, Ltd.

Budiarsih, T. (2019). Keanekaragaman Mikroalga Pada Sumber Air Panas Di Kawasan Taman Nasional Gunung Rinjani Sebagai Bahan Tambahan Praktikum Botani Tingkat Rendah. Hasil Riset tidak Dipublikasi sebagai Syarat Gelar Sarjana, Universitas Mataram, Mataram, Indonesia.

Briand, J. F., Leboulanger, C. \& Humbert, J. F. (2004). Cylindrospermopsis raciborskii Invasion at Mid-Latitudes: Selection, Wide Physiological Tolerance or Global Warming. Journal of Phycology. 40: 231-238. DOI: 10.1111/j.1529-8817.2004.03118.x.

Bravo, I. \& Anderson, D. M. (1994). The Effects of Temperature, Growth Medium and Darkness on Excystment and Growth of the Toxic Dinoflagellate Gymnodinium catenatum From Northwest Spain. Journal of Plankton Research. 16 (5): 513-525. DOI: 10.1093/plankt/16.5.513.

Chapman, V. J. (1962). The Algae. London: Saint Martin's Press Inc.

Fitriana, Y. R. (2006). Keanekaragaman dan Kemelimpahan Makrozoobentos di Hutan Mangrove Hasil Rehabilitasi Taman Hutan Raya Ngurah Rai Bali. Jurnal Biodiversitas, $7 \quad$ (1): 67-72. DOI: 10.13057/biodiv/d070117.

Hutabarat, Sudarsono, P. \& Cahyaningtyas, I. (2013). Studi Analisa Plankton Untuk Menentukan Tingkat Pencemaran di Muara Sungai Babon Semarang. Journal of Management of Aquatic Resources. 2 (3): 74-84. DOI: https://ejournal3.undip.ac.id/index.php/maq uares/index.

Isvanovics, V., Shafik, H. M., Presing, M. \& Juhos, S. V. (2000). Growth and Phosphate Uptake Kinetics of the Cyanobacterium, Cylindrospermopsis racibosrkii in Througflow Culture. Freshwater Biology. 43 (1): 257-275. DOI: 
Lalu Hasan Nasirudin Zohri et al. (2020). Jurnal Biologi Tropis, 20 (3): 355 - 362

DOI: http://dx.doi.org/10.29303/jbt.v20i3.2024

https://doi.org/10.1046/j.13652427.2000.00 549.x.

Kawirian, R. R., Mahrus \& Japa, L. (2018). Struktur Komunitas Fitoplankton Danau Lebo Taliwang Sumbawa Barat. Prosiding Seminar Nasional Pendidikan Biologi. 5059. ISBN: 978-602-61265-2-8.

Kim, Y. J. \& Kim, H. S. (2012). Algal flora of Korea. Volume 6, Number 2 Chlorophyta: Chlorophyceae: Chlorococcales I: Micractiniaceae, Botryococcaceae, Characiaceae, Hydrodictyaceae. Incheon: National Institute of Biological Resources.

Mardani, R., Sudarsono \& Suhartini. (2016). Struktur Komunitas Plankton di Waduk Pandanduri, Nusa Tenggara Barat. Jurnal Biologi. 5 (5): 20-29.

http://journal.student.uny.ac.id/ojs/index.ph p/biologi/article/view/5873 (Accessed on April 1, 2020).

Munthe, Yunita, V., Aryawati \& Isnaini. (2012). Struktur Komunitas dan Sebaran Fitoplankton di Perairan Sungsang Sumatera Selatan. Maspari Journal. 4 (1): 122-130. DOI:

https://doi.org/10.36706/maspari.v4i1.1437.

Nwonumara N. G. (2018). Water Quality and Phytoplankton as Indicator of Pollution in a Tropical River. Proceeding of 6 Nigeria Chapter of Society for Concervation Biology Biodiversity $\quad$ Conference. 83-89. https://www.researchgate.net/publication/32 5108327 Water_Quality_and Phytoplankto $\underline{n}$ as Indicators of Pollution in a Tropica 1_River (Accessed on April 1, 2020).

Odulate, D. O., Ominiyi, T. I., Alegbeleye, W. O., George, F. A. \& Dimowo B. O. (2017). Water Quality in Relation to Plankton Abundance and Diversity in River Ogun, Abeokuta, Southwestern Nigeria. International Journal Enviromental Health Engineering. 6 (3): 1-8. DOI: 10.4103/ijehe.ijehe_31_13.

Odum, E. P. \& Barrett, G. W. (1993). Fundamentals of Ecology Fifth Edition. Boston: Cengage Learning.

Park, J. G. (2012). Algal Flora of Korea Volume 5, Number 1 Cyanophyta: Cyanophyceae:
Chrooccales, Oscillatoriales. Incheon:

National Institute of Biological Resources.

Purwati, S. U. (2016). Karakteristik Bioindikator Cisadane: Kajian Pemanfaatan Makrobentik Untuk Menilai Kualitas Sungai Cisadane. Ecolab. 9 (2): 47-104. E-ISSN: 2502-8812.

Rissik, D., Senden, D. V., Doherty, M., Ingleton, T., Ajani, P., Bowling, L., Gibbs, M., Gladstone, M., Kobayashi, T., Suthers, I. \& Froneman, W. (2009). Plankton: A Guide to Their Ecology and Monitoring for Water Quality. Canberra: Commonwealth Scientific and Industrial Research Organization Publishing.

Romimohtarto, K. \& Juwana, S. (2007). Biologi Laut Ilmu Pengetahuan Tentang Biota Laut. Jakarta: Djambatan.

Sahoo, D., \& Seckbach, J. (2015). The Algae World. New York: Springer Science Business Media Dordrecht.

Simanjuntak, M. (2009). Hubungan Faktor Lingkungan Kimia Fisika Terhadap Distribusi Plankton di Perairan Belitung Timur Bangka Belitung. Jurnal Perikanan. 11 (1): 31-45. DOI: https://doi.org/10.22146/jfs.2970.

Suriadarma, A. (2011). Dampak Beberapa Parameter Faktor Fisik Kimia Terhadap Kualitas Lingkungan Perairan Wilayah Pesisir Karawang Jawa Barat. Riset Geologi dan Pertambangan. 21 (2): 21-36. DOI: 10.14203/risetgeotam2011.v21.43.

Tomas, C. R. (1997). Identifying Marine Phytoplankton. San Diego: Academic Press.

Wijaya, T. S. \& Hariyati, R. (2011). Struktur Komunitas Fitoplankton sebagai Bioindikator Kualitas Perairan Danau Rawapening Kabupaten Semarang Jawa Tengah. Anatomi Fisiologi. 19 (1): 55-61. DOI: https://doi.org/10.14710/baf.v19i1.2584. 